\title{
ChemComm
}

\section{Solvatochromic probes for detecting hydrogen-bond-donating solvents $\dagger$}

Cite this: Chem. Commun., 2014 50,4579

Received 29th January 2014, Accepted 14th March 2014

DOI: $10.1039 / \mathrm{c} 4 \mathrm{cc} 00805 \mathrm{~g}$

www.rsc.org/chemcomm

Hydrogen bonding heavily influences conformations, rate of reactions, and chemical equilibria. The development of a method to monitor hydrogen bonding interactions independent of polarity is challenging as both are linked. We have developed two solvatochromic dyes that detect hydrogen-bond-donating solvents. The unique solvatochromism of the triazine architecture has allowed the development of probes that monitor hydrogen-bond-donating species including water.

Solvatochromic probes are important in the study of solutesolvent interactions. The function of these probes depends on the overall solvation process around the solute. ${ }^{1}$ Solvent characteristics, such as polarity and hydrogen-bonding, influence molecular conformations, reaction rates, and system chemical equilibria. ${ }^{2}$ In addition, both polarity and hydrogen bonding are major contributors to the stabilization of protein folding and binding sites. ${ }^{3}$ Previously, organic fluorescent dyes possessing solvatochromic properties have been used to investigate environmental changes in biomembrane imaging, ${ }^{4}$ ion sensing, ${ }^{5}$ and oil-water interface applications. ${ }^{6}$

The spectral shifts of current solvatochromic dyes are influenced by both dipole interactions and hydrogen bonding. ${ }^{7}$ These dyes cannot distinguish between the two interactions, which makes assessing the response of each interaction to environmental change difficult. This lack of specificity complicates the use of the dyes in monitoring hydrogen-bond strengths, ${ }^{8}$ hydrogen-bond-based conformation changes, ${ }^{9}$ and detecting water and other hydrogen-bonddonating species. ${ }^{10}$ Development of a solvatochromic dye capable

\footnotetext{
${ }^{a}$ Department of Chemistry, University of Massachusetts, 710 North Pleasant Street, Amherst, Massachusetts, USA. E-mail: rotello@chem.umass.edu

${ }^{b}$ WestCHEM, School of Chemistry, Joseph Black Building, University of Glasgow, Glasgow, G12 $80 Q$, UK

$\dagger$ Electronic supplementary information (ESI) available: Quantum yield of MADAT in DCM and methanol. Emission of MADAT in phenol and trifluoroethanol. AMADAT emission in various solvents. Linear correlation between concentration of thymine $\mathbf{1}$ and fluorescence intensity. Addition of $N$-Me thymine 2 to MADAT in DCM. Linear relation between water concentration and fluorescence intensity. Concentration versus emission plots for MADAT and AMADAT. See DOI: $10.1039 / \mathrm{c} 4 \mathrm{cc} 00805 \mathrm{~g}$
}

of monitoring how hydrogen bonding influences overall structure, independent of polarity, is therefore desirable.

Here, we report the development of organic dyes, 6-(3-aminophenyl)-1,3,5-triazine-2,4-diamine (MADAT) and its acetylated analog, AMADAT, which have the ability to detect hydrogen-bond-donating solvents. While the emission shift of both MADAT and AMADAT is largely unchanged in all aprotic solvents regardless of polarity, these dyes show a significant bathochromic shift in protic solvents. This result shows the potential of these solvatochromic dyes to monitor small changes in protic environments, independent of polarity, by monitoring the bathochromic shift of their emission spectra.

Scheme 1 outlines the synthesis of MADAT and the acetylated analogue, AMADAT. MADAT was synthesized by heating under reflux 3-aminobenzonitrile with dicyandiamide in 1-butanol in the presence of a catalytic amount of potassium hydroxide. ${ }^{11}$ AMADAT was synthesized by treating 3-aminobenzonitrile with acetic anhydride in dichloromethane (DCM) to form $N$-(3-cyanophenyl)acetamide. Next, the acetamide and dicyandiamide was heated to reflux under the same conditions used to synthesize MADAT to form AMADAT. By using commercially available materials, minimal steps, and a simple purification protocol, large-scale synthesis of these dyes can be conveniently performed at a low cost.

a)<smiles>N#Cc1cccc(N)c1</smiles>

b) MADAT<smiles>CC(=O)OC(C)=O</smiles>

Scheme 1 Synthetic steps to (a) MADAT and (b) AMADAT. 

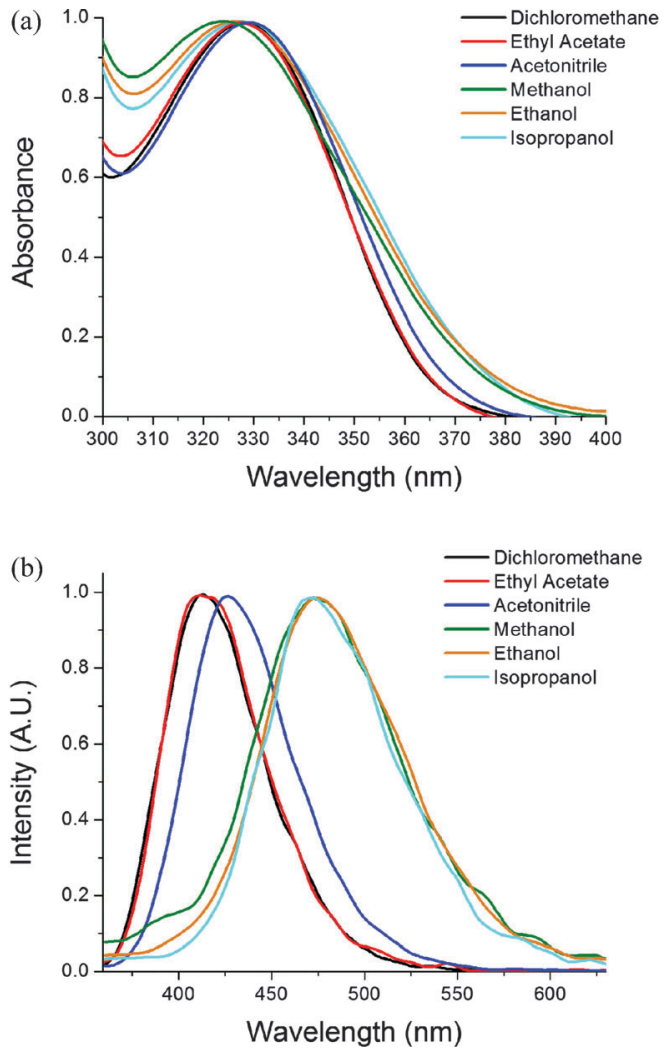

Fig. 1 (a) Normalized absorption and (b) emission spectra of MADAT [0.22 mM], [0.12 mM] (DCM) in various solvents. $\lambda_{\text {ex }}$ : aprotic $=330 \mathrm{~nm}$, protic $=325 \mathrm{~nm}$.

The influence of solvents on the spectroscopic properties of MADAT was determined by UV-Vis absorption and fluorescence spectroscopy (Fig. 1). Minor changes in absorption spectra were observed (Fig. 1a) in either aprotic or protic solvents. In addition, the emission spectrum of MADAT (Fig. 1b) was largely unchanged in aprotic solvents; however a significant bathochromic shift was seen in protic solvents. The same phenomenon was observed for AMADAT (S1, ESI $\dagger$ ). Protic solvents dramatically affected the emission spectrum of these triazine dyes regardless of their chemical structure. Interestingly, strongly hydrogen bond donating solvents such as phenol and trifluoroethanol resulted in complete quenching of MADATs emission (S2, ESI $\dagger$ ).

Emission shifts of solvatochromic materials are the result of environmental changes. As the material is excited by light, solvent molecules align their dipoles with the solute. This realignment can stabilize/destabilize and lower/raise the energy of emission from the solute, causing different light emissions from the same solute in different solvents. Since the emission of MADAT does not greatly shift in aprotic solvents regardless of polarity, there may be no significant stabilization from the solvent or little charge separation within MADAT. The selective response of MADAT to protic solvents could arise from hydrogen-bonding interactions from the diamino units or the nitrogen atoms within the triazine ring. We hypothesize that the triazine ring serves as a multiplehydrogen-bond acceptor and is the cause of the large emission shift. Attention was first directed towards the amino groups of MADAT to rule out hydrogen bonding at these positions.

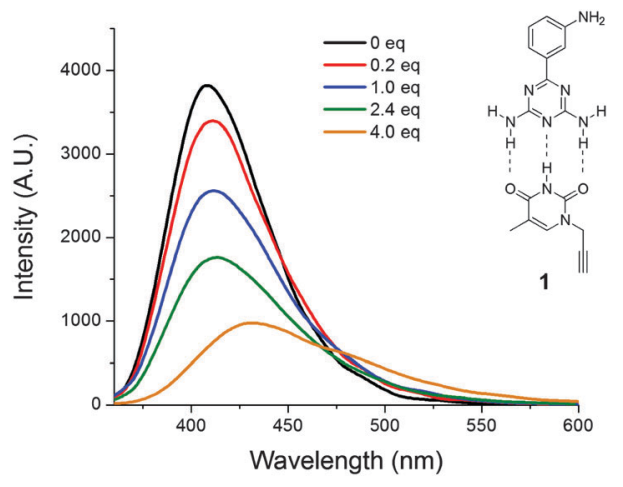

Fig. 2 Thymine 1 additions to MADAT [0.12 mM] in DCM. $\lambda_{\text {ex }}=330 \mathrm{~nm}$.

MADAT was subjected to additions of thymine 1 in DCM (Fig. 2). As the concentration of $\mathbf{1}$ was increased, fluorescence quenching along with bathochromic shifts were observed in the emission spectra. These effects are attributed to the presence of three-point hydrogen bonding between thymine $\mathbf{1}$ and the DAT ring of MADAT. ${ }^{12}$ A linear correlation between the concentration of $\mathbf{1}$ and the fluorescence intensity was observed (S3, ESI $\dagger$ ). As a control, the imide group of $\mathbf{1}$ was methylated before addition to MADAT in DCM; in this case no quenching or shift was observed (S4, ESI $\dagger$ ). Since 1 can only bind to one DAT ring nitrogen atom due to steric effects, we believe that large bathochromic shifts require multiple hydrogen-bond interactions to occur with the triazine ring of MADAT. The need for such multiple interactions would further support the experimental results that showed a more significant emission shift in protic solvents due to the small size of the solvent molecules and their ease of access to the nitrogen ring atoms.

Kamlet-Taft plots are used to distinguish intermolecular interactions between solute and solvent. ${ }^{13}$ This method provides valuable data on how a solute interacts with solvent through both polarity and hydrogen bonding. MADAT can distinguish hydrogen bonding from polarity without the need for Kamlet-Taft plots in both a qualitative and quantitative manner. This solvatochromic phenomenon can be useful in the detection of water in other media. As a proof of concept, MADAT was used to monitor water levels in tetrahydrofuran (THF; Fig. 3). Emission of MADAT in anhydrous THF was observed while adding small aliquots of water. Addition of water resulted in fluorescence quenching and a bathochromic shift in the emission spectra. A linear relation between amount of water added and fluorescence intensity was found (S5, ESI $\dagger$ ), with a detection limit of detection of $0.014 \mathrm{wt} \%$ and a quantification limit of $0.044 \mathrm{wt} \%$.

In conclusion, new solvatochromic dyes demonstrate large bathochromic shifts of their emission spectrum in hydrogenbond-donating solvents only, caused by the presence of the 1,3,5 triazine moiety. These new types of probes therefore have the potential to monitor hydrogen-bonding interactions independent of environmental polarity. We believe that a range of new solvatochromic materials can be readily constructed using the triazine architecture as modification of the aryl amine does not disrupt the solvatochromic properties. This hydrogen-bond-selective solvatochromic feature could prove very useful in developing sensors for hydrogen-bond-donating species. 


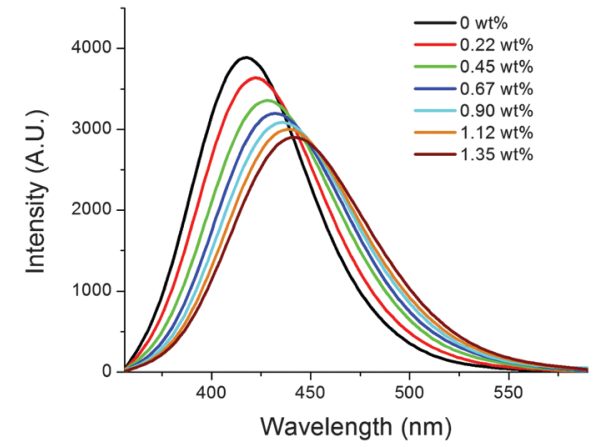

Fig. 3 Changes in fluorescence emission of MADAT [0.22 mM] in THF upon addition of water. $\lambda_{\text {ex }}=330 \mathrm{~nm}$

All solvents and reagents were purchased from commercial sources and were used as received, unless otherwise noted. Deionized water was used in all steps where water was required.

${ }^{1} \mathrm{H}$ and ${ }^{13} \mathrm{C}$ NMR spectra were recorded using a Bruker $400 \mathrm{MHz}$ spectrometer. $\mathrm{mM}$ concentrations were used for absorption and emission spectra, unless otherwise noted. Absorption and emission measurements were performed on a Varian UV-Vis spectrophotometer and a PTI fluorometer respectively using a quartz cuvette.

Synthesis of 6-(3-aminophenyl)-1,3,5-triazine-2,4-diamine (MADAT): To a solution of 3-aminobenzonitrile (1.0 eq., $5.0 \mathrm{~g}, 42.32 \mathrm{mmol}$ ) and dicyandiamide (1.2 eq., $4.27 \mathrm{~g}, 50.79 \mathrm{mmol})$ in 1-butanol $(100 \mathrm{ml})$ was added solid potassium hydroxide $(0.2$ eq., $0.339 \mathrm{~g}$, $8.464 \mathrm{mmol}$ ). The mixture was heated to reflux under atmospheric conditions for $18 \mathrm{~h}$. After the time allotted, the flask was cooled in an ice bath and water $(50 \mathrm{ml})$ was added to fully precipitate the product. The precipitate was filtered off and suspended in hot water $(100 \mathrm{ml})$ and stirred for $5 \mathrm{~min}$. The precipitate was filtered and lyophilized to yield MADAT (89\%). Mp 210-211 ${ }^{\circ} \mathrm{C}$; $\varepsilon$ $2543 \mathrm{M}^{-1} \mathrm{~cm}^{-1}$ (DCM), $1650 \mathrm{M}^{-1} \mathrm{~cm}^{-1}$ (methanol); ${ }^{1} \mathrm{H}$ NMR $\left(\mathrm{CD}_{3} \mathrm{OD}, 400 \mathrm{MHz}\right) \delta: 7.6(\mathrm{~s}, 1 \mathrm{H}), 7.56(1 \mathrm{H}, J=1.2 \mathrm{~Hz}, 1 \mathrm{H}), 7.19$ (t, $J=1.2 \mathrm{~Hz}, 1 \mathrm{H}), 6.88(\mathrm{~d}, J=1.8 \mathrm{~Hz}, 1 \mathrm{H}) ;{ }^{13} \mathrm{C}$ NMR (DMSO, $400 \mathrm{MHz}) \delta: 171.40,167.82,148.87,138.24,128.93,117.09$, 116.20, 113.78; HRMS $m / z(M+H)^{+}$calcd for $\mathrm{C}_{9} \mathrm{H}_{10} \mathrm{~N}_{6}: 203.10$. Found: $\mathrm{M}+\mathrm{H}=203.10$.

Synthesis of $\mathrm{N}$-(3-cyanophenyl)acetamide: 3-aminobenzonitrile (1.0 eq., $5.0 \mathrm{~g}, 42.32 \mathrm{mmol}$ ) was dissolved in dichloromethane $(50 \mathrm{ml})$. Acetic anhydride (1.1 eq., $4.75 \mathrm{~g}, 4.40 \mathrm{ml}, 46.55 \mathrm{mmol})$ was added slowly to the stirred solution and allowed to react overnight. The solution was concentrated under reduced pressure and the mixture dissolved in ethyl acetate $(100 \mathrm{ml})$. The solution was cooled to $0{ }^{\circ} \mathrm{C}$ and saturated sodium bicarbonate was added to the solution and allowed to stir for five minutes. The organic layer was separated and washed twice with brine solution $(50 \mathrm{ml})$. The organic layers were combined, dried with sodium sulfate, filtered, and concentrated under reduced pressure to yield $N$-(3-cyanophenyl)acetamide (97\%) and used without further purification; ${ }^{1} \mathrm{H}$ NMR $\left(\mathrm{CD}_{3} \mathrm{OD}, 400 \mathrm{MHz}\right) \delta 7.71(\mathrm{~d}, J=1.2 \mathrm{~Hz}$, 1H), $7.66(\mathrm{~s}, 1 \mathrm{H}), 7.65$ (d, $J=0.6 \mathrm{~Hz}, 1 \mathrm{H}), 7.34(\mathrm{t}, J=1.8 \mathrm{~Hz}, 1 \mathrm{H})$, $2.21(\mathrm{~s}, 3 \mathrm{H})$.

Synthesis of AMADAT: $N$-(3-cyanophenyl)acetamide (1.0 eq., $3.0 \mathrm{~g}, 18.74 \mathrm{mmol})$ and dicyandiamide (1.2 eq., $1,891 \mathrm{~g}$, $22.49 \mathrm{mmol})$ were dissolved in 1-butanol $(100 \mathrm{ml})$ and solid potassium hydroxide ( 0.2 eq., $0.150 \mathrm{~g}, 3.75 \mathrm{mmol}$ ) was added. The mixture was heated to reflux under atmospheric conditions for $18 \mathrm{~h}$ and cooled in an ice bath. Water $(50 \mathrm{ml})$ was added to fully precipitate the product. The precipitate was filtered off and suspended in hot water $(100 \mathrm{ml})$ and stirred for $5 \mathrm{~min}$. The precipitate was filtered and lyophilized to yield AMADAT (93\%). Mp 276-277 ${ }^{\circ} \mathrm{C} ; \varepsilon 1144 \mathrm{M}^{-1} \mathrm{~cm}^{-1}$ (DCM), $1089 \mathrm{M}^{-1} \mathrm{~cm}^{-1}$ (methanol); ${ }^{1} \mathrm{H}$ NMR $\left(\mathrm{CD}_{3} \mathrm{OD}, 400 \mathrm{MHz}\right) \delta 8.41(\mathrm{~s}, 1 \mathrm{H}), 8.0(\mathrm{~d}, J=1.2 \mathrm{~Hz}, 1 \mathrm{H})$, $7.74(\mathrm{~d}, J=1.2 \mathrm{~Hz}, 1 \mathrm{H}), 7.41(\mathrm{t}, J=2.4 \mathrm{~Hz}, 1 \mathrm{H}), 2.17(\mathrm{~s}, 3 \mathrm{H}) ;{ }^{13} \mathrm{C} \mathrm{NMR}$ (DMSO, $400 \mathrm{MHz}$ ) $\delta: 170.73,168.83,167.85,139.60,138.18$, 128.83, 123.11, 122.31, 119.25, 24.40; HRMS $m / z(M+H)^{+}$calcd for $\mathrm{C}_{11} \mathrm{H}_{12} \mathrm{~N}_{6} \mathrm{O}: 245.10$. Found: $\mathrm{M}+\mathrm{H}=245.5$.

VR acknowledges funding from the NSF (CHE-1307021 and CHE-1025889) and GC acknowledges the EPSRC.

\section{Notes and references}

1 (a) K. Solnstev and D. Huppert, J. Phys. Chem. A, 1998, 102, 9599-9606; (b) C. Reichardt, Chem. Rev., 1994, 94, 2319-2358.

2 (a) C. Bohne, H. Ihmels, M. Waidelich and C. Yihwa, J. Am. Chem. Soc., 2005, 127, 17158-17159; (b) A. Bergen, C. Bohne, D. Fuentealba, H. Ihmels, T. Waidelich, C. Yihwa and J. Bats, Photochem. Photobiol. Sci., 2012, 11, 752-767; (c) H. Ihmels, Eur. J. Org. Chem., 1999, 1595-1600.

3 C. Anfinsen, Science, 1973, 181, 223-230.

4 P. Yan, A. Xie, M. Wei and L. Loew, J. Org. Chem., 2008, 73, 6587-6594.

5 J. Wu, W. Liu, J. Ge, H. Zhang and P. Wang, Chem. Soc. Rev., 2011, 40, 3484-3495.

6 M. Vitha, ACS Symp. Ser., 2011, 1062, 51-97.

7 (a) A. Mehranpour and S. Hashemnia, J. Chin. Chem. Soc., 2006, 53, 759-765; (b) B. Hemmateenejad, M. Yazdani and H. Sharghi, Spectrochim. Acta, Part A, 2012, 91, 198-205.

8 (a) P. Huynh, R. Walvoord and M. Kozlowski, J. Am. Chem. Soc., 2012, 134, 15621-15623; (b) M. Hao, J. Chem. Theory Comput., 2006, 2, 863-872; (c) A. Cuello, C. McIntosh and V. Rotello, J. Am. Chem. Soc., 2000, 122, 3517-3521; (d) J. Carroll, M. Gray, K. McMenimen, D. Hamilton and V. Rotello, Org. Lett., 2003, 5, 3177-3180; (e) K. Matsubayashi and Y. Kubo, J. Org. Chem., 2008, 73, 4915-4919.

9 (a) H. Bock, N. Nagel and C. Näther, Chem. - Eur. J., 1999, 5, 2233-2236; (b) P. Fita, M. Fedoseeva and E. Vauthey, J. Phys. Chem. A, 2011, 115, 2465-2470; (c) D. Cui, X. Qian, F. Liu and R. Zhang, Org. Lett., 2004, 6, 2757-2760; (d) M. Bonn, H. Bakker, A. Ghosh, S. Yamamoto, M. Sovago and K. Campen, J. Am. Chem. Soc., 2010, 132, 14791-14978.

10 (a) M. Wolfshorndl, R. Baskin, I. Dhawan and C. Londergan, J. Phys. Chem. B, 2012, 116, 1172-1179; (b) C. Pinheiro, J. Lima and A. Parola, Sens. Actuators, B, 2006, 114, 978-983.

11 J. Shie and J. Fang, J. Org. Chem., 2003, 68, 1158-1160.

12 (a) B. Jordan, M. Pollier, Y. Ofir, S. Joubanian, J. Mehtala, C. Sinkel, S. Caldwell, A. Kennedy, G. Rabani, G. Cooke and V. Rotello, Chem. Commun., 2008, 1653-1655; (b) N. McDonald, C. Subramani, S. Caldwell, N. Zainalabdeen, G. Cooke and V. Rotello, Tetrahedron Lett., 2011, 52, 2107-2110.

13 M. Kamlet, A. Solomonovici and R. Taft, J. Am. Chem. Soc., 1979, 101, 3734-3739. 